\begin{tabular}{c} 
Volume and Issues Obtainable at Center for Sustainability Research and Consultancy \\
Journal of Business and Social Review in Emerging Economies \\
ISSN: 2519-089X \& ISSN (E): 2519-0326 \\
Volume 7: Issue 2 June 2021 \\
CSRட \\
Journal homepage: www.publishing.globalcsrc.org/jbsee \\
\hline
\end{tabular}

\title{
Incorporation of Vision, Knowledge and Creativity in Innovation and Technology Management: Synthesizing a Sequential Model
}

\author{
*Waheed Asghar, Director in Technical Education and Vocational Training Authority, Lahore, \\ Pakistan \\ Rabia Rasheed, Department of Business Administration, Iqra University Karachi, Pakistan \\ Abdul Aziz Khan Niazi, Institute of Business \& Management, University of Engineering and \\ Technology, Lahore, Pakistan \\ *Corresponding author's email: director.at@tevta.gop.pk
}

\begin{tabular}{l} 
ARTICLE DETAILS \\
\hline History \\
Revised format: Apr 2021 \\
Available Online: May \\
2021
\end{tabular}

\section{Keywords}

Technology, Innovation, Creativity, Knowledge

Management, Vision, Leadership

JEL Classification $\mathrm{O} 0, \mathrm{O3}$ \begin{abstract}
Purpose: The primary objective of the paper is to synthesize the available literature on technology and innovation management in business firms. The study examines and elaborates the sequential relationship between all constructs that ensure innovation and technology management happen in an integrated way. Approach/Design/Methodology: The study employs a qualitative approach of deductive reasoning, based on the reverse engineering method. Existing literature has been used as secondary data to harmonize the constructs as delineated in the conceptual framework for the research. Findings: Several empirical and conceptual studies besides academic contributions have reasonably helped to find that innovation and technology management require essential support of creativity, knowledge and leadership vision. Not only a significant relationship exists but a sequential order is also affirmed for the whole process. Originality / Value: This study presents the mechanism through which organizations can ensure better innovation and technology management. The inclusion of vision, knowledge and creativity in an orderly manner has added another dimension to the subject matter as a new contribution. It will help researchers, academicians and decision-makers to look into the process in a different yet practical manner.
\end{abstract}

(C) 2021 The authors, under a Creative Commons Attribution-

NonCommercial 4.0

Recommended citation: Asghar, W., Rasheed, R. and Niazi, A. A. K. (2021). Incorporation of Vision, Knowledge and Creativity in Innovation and Technology Management; Synthesizing a Sequential Model. Journal of Business and Social Review in Emerging Economies, 7 (2), 343357

\section{Introduction}

For many years, the importance of innovation and technology management is growing in academia, research and practice likewise. The matter has evolved into a full academic subject due 
to its implicit and explicit significance. The reason behind all this development is that organizations especially business firms have identified and discerned innovative ways and means to explore and serve new as well as existing market segments more effectively and efficiently. For this purpose, they may introduce new products or modify the same products including the services. But to let all this happen, there is a need to explore a model to maximize innovation and technological efforts.

Companies concentrating on technology, either in $\mathrm{B} 2 \mathrm{~B}$ or in $\mathrm{B} 2 \mathrm{C}$ markets, are much more influences by newer technologies. Technology retardation poses serious threats to the sustainability of business firms specifically. Management of technology needs leadership attention to set the stage for completion of a complex process, which entails several constructs. These constructs are leadership vision, cultivation of knowledge culture in the organization, creativity, innovation and technology management itself. Although all these constructs are reflected in existing literature, none of the researchers has focused on an integrated approach for a unified model and process. This study has focused to explore a sequential relationship between these constructs that ensures success for technology management and the resultant sustainability of the organization.

Therefore, the objective of the study is to bring in a theory based conceptual framework, which can be utilized in this era's business environment. In order to obtain the purpose, the front-end of technology management has been discussed in conjunction with the relevant theoretical background. Then using the reverse engineering methodology, all-important constructs have been identified in the first instance and later on, a relationship has been developed to converge into an integrated sequential model. In the end, the conclusion has been given as an implication of the conceptual framework.

\section{Literature Review}

The sustainability of any business is the biggest challenge that organizations face from their inception (Gray, 2010). Only those companies survive, for a longer period, which are conscious of innovation and resultant technology adoption. The multilevel framework, and technology and innovation arrangements are theoretically close concepts, which ultimately lead to important consequences and implications for change in technology (Boschma, Coenen, Frenken, Truffer, 2017). A lot many definitions for innovation have produced an equivocalness in the way the concepts of innovativeness and innovation have been operationalized and used in the existing literature about new product development, marketing and management (Garcia \& Calantone, 2002). A survey of the literature in the fields of marketing, new product development as well as engineering has given a bit of clarity to the application of these concepts. Nevertheless, a perspective of marketing and technology, as well as macro-micro level has been taken into account while describing innovations.

Innovation is thinking of unique and creative ideas which when implemented produce effective results towards the solution of a problem (Fagerberg, Mowery and Nelson, 2005). To let the innovation prevail, people in the organization must be sufficiently creative to think otherwise than the prevailing mindset. Creativity can be described as an activity of transforming ingenious thoughts into reality. In other words, it is the mental ability to conceive the world in new and different ways, to discover obscure patterns, and to establish connections between apparently uncorrelated phenomena, and to find out solutions for seemingly unresolvable problems. Having the capacity to think and produce differently requires knowledge and the cultivation of a knowledge culture within an organization is a substantive requirement (Lee and Park, 2005). Learning organizations make the tacit knowledge of individuals available for organizational purposes. In the whole process, the role of leadership becomes predominantly significant as only an enabling vision can transform an organization into an innovative entity that is technologically capable and 
competitive as well (Abbas \& Asghar, 2010).

From the perspective of the above discussion, it can be noted that there are different constructs to innovation and resultant technology management. The constructs in this whole process are an innovation that is directly dependent upon creativity, which itself relies upon knowledge. None of the constructs will be fostered in any organization until it has a leader having a clear vision to cultivating such a supportive culture.

In the existing literature, the matter has been discussed but in bits and pieces. Akram, Siddiqui, Nawaz, Ghauri, and Cheema (2011), for example, posited that knowledge success factors are important in diffusing knowledge between employees, which tones up the organizational knowledge culture. They maintained that for boosting the process, firms should carry out the determinants of innovation that are the exact reasons for the innovation itself. But in their research, they did not consider other determinants that they mentioned. In another study, Koellinger (2008) attempted to discover the relationship between technology and innovation in relation to firm performance but did not include all necessary constructs.

In another research, Martins and Terblanche (2003) propounded the relationship between innovation, creativity, and organizational culture. In a conceptual framework engaging these determinants, they presented a background of their model and identified the determinants of organizational culture. They discovered the determinants like structure, support mechanism, behavior, and strategy, which boost open communication culture, and resultantly innovation. In a recent study, Sarooghi, Libaers \& Burkemper (2015) also worked on the correlation between innovation and creativity and propounded a multi-level analysis of organizational, environmental and cultural aspects for exploring this correlation. Their research conforms to the previous findings that a firm correlation exists between innovation and creativity, not only at the individual level in an organization but also at various levels of the technology being used.

Gurteen (1998) in his research established a relationship between creativity, innovation, and knowledge. According to Gurteen, creativity and innovation are dependents upon knowledge management. He very lucidly expounded the bottlenecks in the way of innovation through creativity and knowledge but did not discuss the impact upon technology and the vision of the leadership.

Some researchers have focused the innovation-related knowledge, creativity and resultant innovations e.g. Cohendent \& Parmentier et al., (2017) contend that management of creativity is equal to management of ideas. They further argue that the major bottleneck at this stage is capturing the imaginative ideas from human brains that are like a Blackbox. They proposed a structured framework but without a sequential relationship.

Similarly, some literature is available about the relationship between technology and innovation. For example, Smith, Busi \& Van der Meer (2008) maintain that technology facilitates innovation and vice-versa but neither technology nor innovation alone is sufficient for the process to ignite and consummate. In their view, technology with the utilization of technical skills, education, and strategy make a strong base for innovation.

To conclude, although existing literature has reasonably deliberated on all important constructs of innovation and technology advancement as given above, yet severally in segments. Some of the studies have included knowledge and creativity in the discussion as well. But no deliberations are made to encompass all the essential constructs in a single study. Similarly, no study is available that depicts the logical and rational sequential relationship for giving a vivid and clear picture to make innovations and technology changes more practicable for businesses. 


\section{Conceptual Framework}

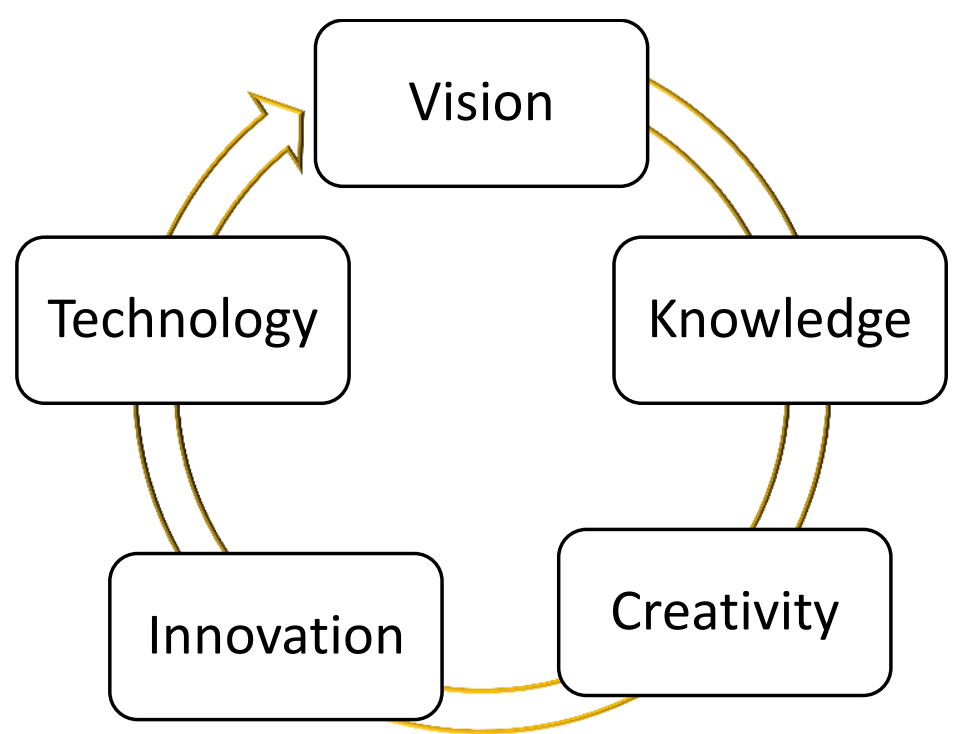

Figure 1: Sequential Model of Antecedents to Innovation and Technology Management

A more detailed, integrated and sequential model has been delineated taking into account all important constructs keeping in view the purpose of the study, which is to explore all important antecedents to innovations, and resultant technology management. A rudimentary approach is required to delve into all requisites, which are considered the sine qua non to ignite and complete the whole process. To logically synthesize the model in a natural sequence, the deductive reasoning approach, based on the reverse engineering method, will be employed to explore the entire process with requisite antecedents. Let us start the discussion with technology and its management.

\section{Technology}

Technology can be generally defined as immaterial and material entities, produced by utilizing physical and mental processes for creating some value (Faulkner and Runde, 2011). Technology may involve the use of tools and machines, which is ultimately utilized for solving real-world issues (Yli-Renko and Janakiraman, 2008). Consistent technology development is worthwhile so far as it is valuable to the customer. That is why the management in a firm must have the capacity to analyze and decide when to invest in technology and when to divest (Schilling, 2002). Management of technology can also be described in terms of integrated planning, operationalization, and control of technology products and their optimization, and the end purpose of any technology is its use for human advantage (Betz, 2003).

One way to manage the technology may be Technology Watch (TW). Product and services organizations both can constantly track emergent technologies and applications in an attempt to maintain core competencies in technological areas particularly where they have an edge. The major objective of this TW technique is to keep an eye on the technological advances of other similar organizations. It will help to collect and retrieve data that can help to make a similar decision on technology adoption or adaption, investment, cooperation, and competition strategies (Lee and Park, 2005). Even if viewed apparently, the adoption of the TW technique will be a defensive approach instead of an offensive one.

Extensive Research and Development is another mode that may contribute to technological developments. In their research, Brady, Rush, Hobday, Davies, Probert, and Banerjee (1997) have emphasized that competitive performance is dependent upon investment in technological initiatives through R\&D. But sparing only the resources to the activities about innovation like 
R\&D is insufficient. Many such organizations still have failed to manage the technology advancement successfully.

Another way to technology development rather acquisition is technology cooperation outside the organizational boundaries. Typically, the cooperation between business entities is viewed in terms of the vertical relationship for economic exchange (Hagedoorn, 1997). However, modern organizations develop a linear relationship for sharing advancement of research and diffusion of scientific-technological knowledge amongst participating companies. Some motives are related to the increased complexity and intersectional nature of new technologies and the cross-fertilization of scientific disciplines and fields of technology (Hagedoorn, 1997). But the cardinal debate remains intact i.e. does this cooperation and relationship guarantee the continuous technology advancement to a firm for a sustainable competitive advantage? Those that have been successful have not only devoted resources to technology; they have also learned to manage innovation (Brady \& Rush et al. 1997). If the innovation process is well maintained in an organization, it will ensure such technological advancement ensuring vantage in terms of competition. So, the management of the innovation process internally within the organization can be recognized as the herald to technology management.

\section{Innovation}

Innovation can be described as the implementation of newly created ideas for generating business value. More precisely, innovation is about utilizing new ideas and turning them into something useful and practical. So, it is a process of converting theory into action. However, the process may be having three basic dimensions. Firstly, it may be changing, improving, or replacing the procedures of business for increasing productivity or enabling a firm to enhance the range of quality services and products. Secondly, there may be the development of altogether new better products or services by bringing in technology breakthrough. Thirdly, it may be an addition to the existing portfolio of products or services or the markets as a whole by differentiating from competitors and increasing the perceived value to the markets and the customers. Nevertheless, the most common style of innovation is scalable, which implies finding ways to create incremental improvements to your products and services. Fancis and Bessant (2005) have summarized all these dimensions under four Ps. His P1 refers to innovation for introduction or improvement of products; P2 is innovation regarding introduction or improvement in processes; P3 is innovation for defining or re-defining the positioning of the products of a firm, and; P4 refers to innovation for defining or re-defining the prevailing paradigm of the firm. Fancis and Bessant (2005) also identified two kinds of innovations i.e. "do-better" innovation and "dodifferent" innovation and professed for attaching more focus to the latter one as it brings a radical shift to new products and perhaps for the industry as well.

A lot of research is available about the success and failure of innovations that provide some hints as to bring improvement in innovation and technology management. This plethora of research provides an opportunity to extract a long list of factors, characteristics, capabilities, and mechanism that organizations may require to put in place for becoming successful innovators. Mogee (1993) points out that firms for the most part do not recognize innovation management as a matter to focus deliberately in a systematic way. Innovations need a team of employees to include engineers, sales and marketing personnel, investors, business planners and financial experts and managers. The way to organize a set of employees capable to introduce new imaginative ideas from a discussion place or a laboratory to the market provides a real opportunity to incorporate innovation management discipline in the organization.

So, it becomes obvious that firms require to build the capacity for exploring out-of-the-box and thinking and explore the crucial do-different as propounded by Francis and Bessant (2005). It 
refers to the capacity of the employees in terms of innovation potential and to deal with the challenge of generating creative ideas. Zhong, Mei, and Xie (2009) posit that creativity and innovation have attained greater significance in the workplace as these are being considered as important determinants of a firm's sustainability over a long time due to its ever-increasing performance and success. As an organization strives to discover the process for the generation of imaginative ideas and their implementation, creativity becomes a permanent source, which ensures competitive advantage in the form of continuous innovation (Zhou and Shalley, 2003; Anderson, De Dreu, and Nijstad, 2004). The next section, therefore, explores creativity and its management attributes.

\section{Creativity}

Sternberg and Lubart (1999), while defining creativity, describe it as the capacity to produce something novel (i.e. unexpected as well as original) and appropriate (adaptive, useful, and concerning task limitations). It capacitates business firms to discover something new that may be a complete breakthrough. To let this happen, it is required that blur and collisions take place to trespass bounds established by the disciplines. In this way, it will become easy for a firm to obtain new ways and means to solve technical, operational, financial or marketing problems.

Recently, the creative worker role has been identified and evolved. In an amazing development, knowledge workers are being replaced with creative workers, which explicitly mean that just acquiring knowledge is of no avail. Management of creative teams and inspiring diversity has become a necessary part of the role of a team leader. Even ordinary workplaces have the potential to innovative and creative in their workflows. The management role is much more scrupulous in managing creativity in an organization. Amabile and Khaire (2008) questioned whether management was "a net positive or a net negative" for creativity. "If there is a bottleneck in organizational creativity," they inquired. "Might it be at the top of the bottle?" they continue to comment. One thing that is as clear as daylight is that one manages for creativity instead of managing creativity.

The foremost important thing in managing creativity is engaging the right persons at the right time to the right degree in creative tasks. Instead, a bottom-up approach is required in place of a top-down strategy. Tapping ideas from all levels in the organization is an essential condition. To create synergies, there should be then a fillip for collaborations as most innovations are drawn through contributions instead of individual breakthroughs.

Another important factor for creativity is opening the organization to a variety of perspectives. When employees with different backgrounds, disciplines, and experts share their ideas, innovations are most likely to take place. Often, the ramification of a problematic issue demands diversity like engaging people having different background like mathematicians, designers, medical doctors, neuroscientists, electrical and electronics engineers, etc. It may also happen that the use of experience and method of one field or area may bring a breakthrough for another field or area facing a particular or seemingly problem.

If intellectual challenge and independence are indeed the keys to creativity, leadership must find ways to deliver it. For the most part, this requires awareness of people's interests and skills. When people are good at a project, giving them independence comes with less risk. Ideally, workers having a creative bent of mind would be able to define their plans, at least in part. So, in essence, the knowledge of individual people in an organization becomes more important to pave the way for creativity.

Brinck (1999) views creativity as a cognitive activity. According to him, it involves much the 
same elements as problem-solving, that is, knowledge-representations, rules for manipulating knowledge, standards for evaluating solutions, and a halting rule that puts an end to the search. Prendergast (2000) maintains that problems arise when knowledge is incoherent or insufficient, in the sense that there is a clash or a lacuna among the set of representations supposed to cover a certain area. According to many researchers, academicians, and practitioners without knowledge, the objectives of creativity and innovation cannot be realized (Malecki, 2010; Vehar, 2013; Park and Lee, 2014; Mohtar, Halmin \& Sulaiman, 2015; Bontje \& Musterd, 2016). "One cannot think creatively unless one has the knowledge with which to think creatively. Creativity represents a balance between knowledge and freeing oneself of that knowledge" (Sternberg, 2012). Gieras, (2019) depicts the interplay of knowledge and creativity in Figure 2.

\section{Knowledge}

Knowledge can be described as theoretical or practical comprehension of a discipline. Prusak and Davenport (1998) described knowledge as a product of formed experiences, values, contextual information, and expert opinions that provide a basis for evaluating and incorporating new information and experiences. More precisely, knowledge refers to the understanding of a matter by

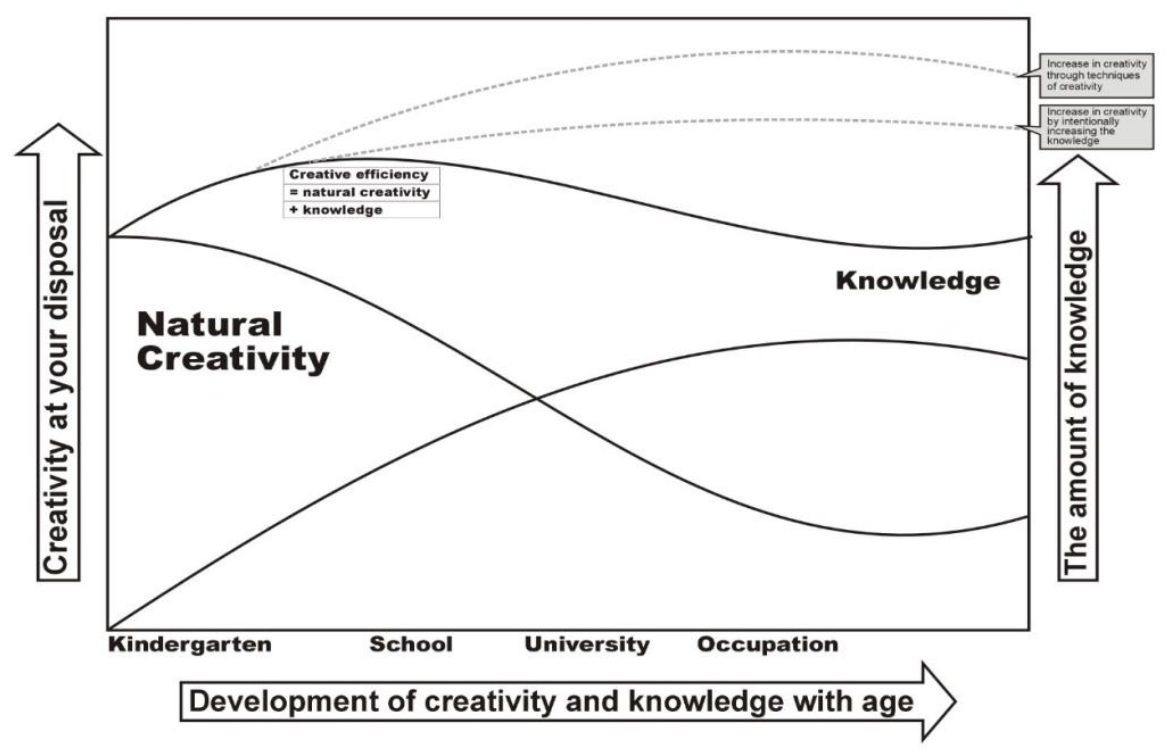

Figure 2. The Interplay between knowledge and creativity

theory or practice. It may be explicit (as with the theoretical understanding of the subject) or implicit (as with practical skill or expertise). Looking from another perspective, it can be more or less systematic and formal. In the organizational context, the management of knowledge is more important than the mere its excogitation.

Knowledge management is for the most part similar to knowledge sharing. In that sense, knowledge management is converting 'Tacit Knowledge' to 'Explicit Knowledge'. Tacit knowledge is explained as knowledge in someone's head that looks like a black box. Hence, it is difficult to get tacit knowledge as it is in the form of skills, abilities, thoughts and ideas in the minds of people. Tacit knowledge cannot be disseminated among members of an organization if it is not applied and practiced by those who have it in their heads. On the other hand, it is easy to capture explicit knowledge. Similarly, it is easy to capture, disseminate and share amongst members of the 
organization in the form of soft and hard data, defined procedures as well as standardized principles (Akram \& Siddiqui et al., 2011).

To cultivate a knowledge management culture in an organization, different activities are required. Neilson (2006) identified eight activities that are knowledge creation, its acquisition, capturing, aggregation, sharing, integration, leveraging and exploration. He further divided these activities into three classes like knowledge development, knowledge combination and knowledge usage. All these activities help to obtain knowledge from within the outside the firm increasing the overall value for the organization as illustrated in Figure 3.

Besides, these activities ensure to enrich the knowledge assets and the repository of the organization. Equally important concepts to unleash the potential of knowledge cultivation are organizational unlearning and organizational relearning. According to Zhao, Lu, \& Wang (2013) "these are the indispensable factors to the dynamic knowledge management. Organizational unlearning positively affects the dynamic knowledge management by discarding the outdated and useless knowledge, while organizational relearning has a positive influence on the dynamic knowledge management by acquiring the new knowledge". This organizational learning and unlearning have a synergetic effect on knowledge management.

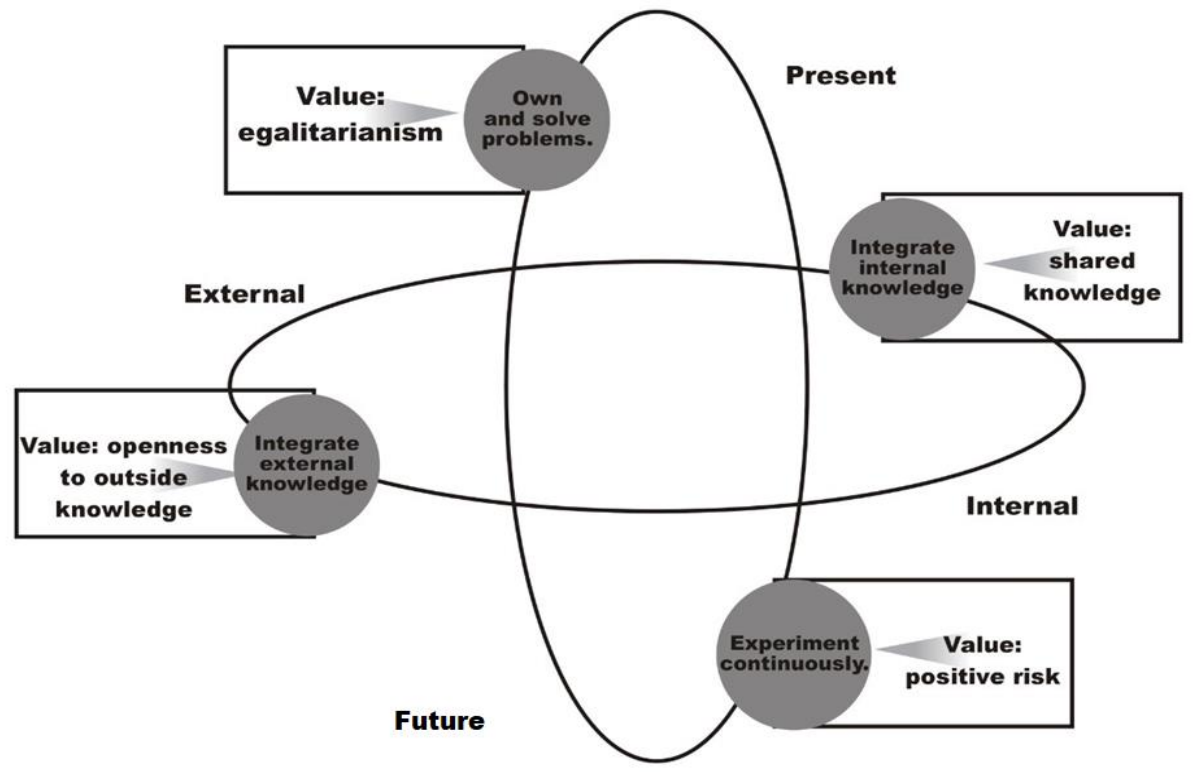

Figure 3: The Knowledge Value Model

When this continuous yearn for knowledge becomes a routine matter, it becomes a conspicuous culture. But this is not perhaps an easy task to establish and cultivate a culture that converts the organization into a progressive and modern entity paving the way for creativity and innovation. Janz and Prasarnphanich (2003) write, "Organizational culture is believed to be the most significant input to effective knowledge management and organizational learning in that corporate culture determine values, beliefs, and work systems that could encourage or impede knowledge creation and sharing" And who is going to establish such a supportive culture? The top leadership, as we all know. The role of a leader in developing and promoting a knowledgesharing culture by creating a continuous learning environment at the individual and organizational level is very crucial. This can be done by developing a knowledge promoting system and structure through visionary thoughts and wise decisions accordingly. The next section expatiates the role of vision in the process.

\section{Vision}

The term "vision" sometimes is expressed with words like "personal agenda, dream, goal, purpose, legacy, or imaginativeness". Some other terms have been cited like long term goals, 
long term objectives, images, doctrines, and core ideology (Price, 2001). It defines the core values and activities that differentiate organizations from one another. It is defined as a statement of purpose, as described by management based on the core values and beliefs of the organization, specifies its identity, and combines the ideal expression of its direction with a real recipe for achieving its goals (Ford and Pasmore, 2006).

McGyvern and Tworick (1998) argue that the traditional concept of organizational vision has been presented in two different contexts. In the first, vision is seen as an approach that determines business strategy, and in the second, as an approach that contributes to the development of organizational culture. Putting it another way, as posited by many scholars and practitioners, a significant constituent of culture is corporate vision (Melewar \& Jenkins 2002; Lee, Kim \& Jun, 2007). A vision that diffuses through the organization can extend to the employees a requisite sense of purpose, which transcends everyday activities to include knowledge creation, diffusion and sharing. According to Rahimnia, Moghadasian \& Mashreghi (2011), the overall vision is intended to generate clear organizational goals and helps to bring in essential changes in the organization so that it can attain its intended future objective of sustainability. The vision can envisage not only a statement that demonstrates a clear and unambiguous direction of the organization, but it can also integrate corporate culture that promotes knowledge, creativity and innovation. Through a well-phrased and well-communicated vision, it is ensured to engender a sense of participation and contribution amongst organization members (Rahimnia \& Moghadasian et al., 2011).

\section{Sequential Relationships between Different Constructs \\ Relationship between Vision and Knowledge}

Knowledge is something organic and alive. It is like a stream, which flows between people who are facing up a challenge or are in any disruption or disturbance in specific circumstances, with shared norms, values and language that enable them to reach their purpose efficiently, adeptly, and eagerly. Every organization may take the form of an ecosystem provided the solutions are constructed jointly with real-time commitments and without roadblocks and even bottlenecks. Here leaders act as motivators, conveners, and facilitators of agile conversations with a clear vision of laying out knowledge stream (Wieneke \& Phlypo-Price, 2010). Vision accompanied by corporate values system ascertains the requisite type of knowledge and knowledge related activities that are endured and promoted. Explicitly stated vision can promote the outgrowth of knowledge within the organization. Then openness and trust are mostly cited as two of these explicated values, which encourage knowledge management behaviours. Generally, a focus on the vision statement and value systems should be placed on the organization components that promote effective knowledge management. However, the creation of a vision and set of organizational values is not enough. They must be effectively communicated throughout the organization (Gold, Malhotra and Segars 2001).

\section{Relationship between Knowledge and Creativity}

Once the vision establishes the ground for the proliferation of knowledge, the latter will sprout creativity in the organization. There are confronting theories concerning the mechanisms underlying creative thinking and the role of knowledge in creativity. Although certain approaches present a contradictory relationship between creativity and knowledge, yet for the most part a positive relationship has been posited by researchers and practitioner. In his research Weisberg (1999) concluded at extensive domain-specific knowledge is a prerequisite for creative functioning. He further suggests that we need to change how we conceptualize the conflicting or undermining relationship between creativity and knowledge.

Many other researchers have explored a significant positive correlation between commitment to knowledge management and employees' creativity (see for example Ardakani, Damaki, Nasab 
and Golkarieh, 2008; Mosloo, Damneh \& Jalilian, 2009; Azari, Baryamani and Gholikani, 2011) concluded that there is a significant correlation between creativity and knowledge management. In their experimental research on a product design project, Christiaans \& Venselaar (2005) concluded that strong a relationship was discovered between the amount of knowledge utilized and the creative design. There is a resultant inclination for subjects whose designs have a higher creativity rating to elicit on average a greater amount of both implicit and explicit knowledge than other participants. What is the meaning of this relationship? They explained that the participants, who obtained the required knowledge and are guided by it, are more capable to generate solutions that are creative in principle. So, at this stage, it can be concluded that to manage creativity in the organization, first we need to manage the promotion of requisite knowledge in the organization as a culture.

\section{Relationship between Creativity and Innovation}

It is generally considered that creativity opens the way for innovative activities. Empirical studies of the effects of creativity on innovation, while positive, have yielded extensive results. In their study, Sorogi, Labers, Berkemper (2015) examined this relationship empirically and particularly focused on how organizational, environmental and cultural factors, in particular, inhibit creative innovation. They discovered a strong positive relationship between creativity and innovation particularly at the individual level. Heunks (1998) finds an interesting moderating effect in which the correlation between creativity and innovation is stronger for large firms, process innovations, and low-tech industries relative to small firms, product innovations, and high-tech industries.

It has been suggested by the researchers and academicians that creativity necessitates the cognitive processes to initiate primarily in the minds of individuals-hence an intra-individual activity; whereas innovation, for the most part, corresponds to the intra-individual social process in the workplace (Rank, Pace \& Frese, 2004). In short, creativity centres around idea generation but innovation focuses upon idea implementation. Creativity, therefore, is mostly seen as the opening requisite move towards innovation (Anderson, Potočnik \& Zhou, 2014; Amabile, 1996; Mumford \& Gustafson, 1988; West, 2002).

\section{Relationship between Innovation and Technology}

There is an agreement amongst researchers, academicians and practitioners that technological innovations largely depends upon the innovation capabilities of a particular organization or the so-called innovation potential (see for example Moore \& Benbasat, 1991; Gurbiel, 2002; Pavitt 1999, Plewa, Troshani, Francis, \& Rampersad 2012). According to Gurbiel (2002), Innovation should be generally perceived as everything, which is the result of practical primary usage of a certain idea called creativity. In their study, Plewa \& Troshani et al. (2012) while discussing technology adoption posit that innovation diffusion is complementary for this process to start and complete. They consider innovation diffusion as a societal system and behavioural process that guide the organizational members to adopt or adapt to new technology or modify, at least, the existing one. The innovation environment within the organization helps to improve not only developing or acquiring new technology but also supports the understanding relative advantages of complexity, trialability, and compatibility of technology adoption (Rogers, 2003). Some researchers go to the extent of arguing that innovation diffusion and technology adoption cannot go in the silo as the integration of both is unavoidable (Agarwal \& Prasad, 1998; Cheng and Cho, 2010).

The relationship between innovation and technology is so much robust even the type of innovation impacts the manifestation of technology. For example, incremental innovations exploit the potential of established designs and often supports the supremacy of already dominating companies. They refine the existing functional capacities of technology through small scale improvements by adding value and augmenting attributes like quality, performance, safety 
reducing the overall cost. On the other hand, radical innovations, bring in new concepts that go away from the past and traditional practices and support processes and products bases upon varying concepts of science and engineering and often introduce entirely new potential applications and resultantly products and markets (Henderson \& Clark, 1990). Interestingly innovation has been defined as "the commercialization of new products and technologies that have a strong impact on the market, in terms of offering wholly new benefits, and the firm, in terms of its ability to create new businesses." (O'Connor \& Veryzer, 2001). To conclude, those who have been successful have not only devoted resources to technology; but they first learned to manage innovation for success.

\section{Relationship between Technology and Vision}

Technology appears to be one of the most powerful drivers of change in the environment of organizations. Advances in science and technology are important factors influencing the worldview of organizations. Delphi's wide range of technology research and research in nearly all industrialized countries strongly suggest that the impact of an overarching technological vision and related developments will increase significantly in the coming decades (Anderson \& Potocnik et al., 2014).

The importance of technology for the development and survival of organizations is steadily increasing due to the frequency of their use and due to the ever-increasing use and application of new technological and scientific developments (Betz, 2003). These developments, in turn, improve the way business is conducted and the corresponding changes in the vision and mission statements of companies. This is perhaps a natural phenomenon, as technological developments are causing great changes in organizations, customer expectations, and even in society at large. The integration of the new overarching vision into the organization is guided and shaped by the existing vision of the organization, which is modified by that very technological process itself (Bases, 2003).

\section{Conclusion}

The purpose of this study was to explore an integrated approach for innovation and technology management taking into account other factors that play important role in the whole process that was lacking before. There are several components involved in this model like technology, innovation, creativity, knowledge and knowledge culture, and the vision. The existing literature extensively supports the model which was delineated and presented in Figure 1. There are several components involved in this model that are interconnected sequentially. There are several components involved in this model which are interconnected sequentially. The way to technology up-gradation and adoption goes through innovation, which is directly dependent upon creativity. But for creativity to take place, employees in the organization must have plenteous knowledge. To let all the factors play their due role, the support of visionary leadership is a sine qua non. When an incremental or new technology is introduced or adopted, it helps to revisit the vision and vision statement of the organization that again triggers the whole process from knowledge management to technology management and vision in sequential order. 


\section{References}

Abbas, W., \& Asghar, I. (2010). The role of leadership in organizational change: relating the successful organizational change with visionary and innovative leadership. Masters Thesis. The University of Gavle.

Agarwal, R. and Prasad, J. (1998). A conceptual and operational definition of personal innovativeness in the domain of information technology. Information Systems Research, Vol. 9 No. 2, pp. 204-15.

Akram, K. Siddiqui, SH. Nawaz, MA. Ghauri, TA. and Cheema, AKH. (2011). Role of knowledge management to bring innovation: an integrated approach, International Bulletin of Business Administration 11, 121-134

Amabile, T. M., \& Khaire, M. (2008). Your organization could use a bigger dose of creativity. Harvard Business Review, 86(10), 101-109.

Amabile, Teresa M. (1996). Creativity and Innovation in Organizations."Harvard Business School Background Note 396-239. https://www.hbs.edu/faculty/Pages/item.aspx? num $=13672$

Anderson, N., De Dreu, C. K., \& Nijstad, B. A. (2004). The routinization of innovation research: A constructively critical review of the state-of-the-science. Journal of Organizational Behavior. 25(2), 147-173.

Anderson, N., Potočnik, K., \& Zhou, J. (2014). Innovation and creativity in organizations: A state-of-the-science review, prospective commentary, and guiding framework. Journal of management. 40(5), 1297-1333.

Ardakani, S., Damaki, A. M., Nasab, S. H., \& Golkarieh, S. (2008). Investigate the correlation rate between commitment to knowledge management and employee creativity (case study: Yazd University employee). Paper presented at First National Conference of creativity, TRIZ (TRIZ), Engineering and Innovation Management, Iran. November.

Azari, K. N., Baryamani, A., \& Gholikhani, B. S. (2011). Investigate the role of manager on creativity in secondary schools. Journal of Researcher, 3(21), 79-86

Bases, T. (2003). Technological visions, technological development, and organizational learning. Handbook of organizational learning and knowledge, 282.

Betz, F. (2003). Managing technological innovation: competitive advantage from change. John Wiley \& Sons.

Bontje, M., \& Musterd, S. (2016). Inventive city-regions: Path dependence and creative knowledge strategies. Routledge.

Boschma, R., Coenen, L., Frenken, K., \& Truffer, B. (2017). Towards a theory of regional diversification: combining insights from Evolutionary Economic Geography and Transition Studies. Regional studies. 51(1), 31-45.

Brady, T., Rush, H., Hobday, M., Davies, A., Probert, D., \& Banerjee, S. (1997). Tools for technology management: an academic perspective. Technovation, 17(8), 417-426.

Brinck, Ingar (1999). Procedures and Strategies: Context-dependence in Creativity. Philosophica 64 (2):33-47.

Cheng, S. \& Cho, V. (2010). An integrated model of employees' behavioural intention toward innovative information and communication technologies in travel agencies. Journal of Hospitality \& Tourism Research.

Christiaans, H., \& Venselaar, K. (2005). Creativity in design engineering and the role of knowledge: Modelling the expert. International Journal of Technology and Design Education, 15(3), 217-236.

Cohendet, P. Parmentier, G. \& Simon L. (2017). Managing knowledge, creativity and innovation. In Bathelt, H. Cohendet, P. Henn, S. and Simon L. The Elgar Companion to Innovation and Knowledge Creation, Pages 197-214, Edward Elgar Publishing, DOI: https://doi.org/10.4337/9781782548522.00021

Davenport, T. H., \& Prusak, L. (1998). Working knowledge: How organizations manage what they know. Harvard Business Press. 
Fagerberg, J., Mowery, D. C., \& Nelson, R. R. (Eds.). (2005). The Oxford handbook of innovation. Oxford university press.

Faulkner, P., \& Runde, J. (2011). The social, the material, and the ontology of non-material technological objects. In European Group for Organizational Studies (EGOS) Colloquium, Gothenburg, Vol. 985, pp. 4-8.

Ford, C. M. (1995). Creativity is a mystery. Creative action in organizations, 12-52.

Francis, D., \& Bessant, J. (2005). Targeting innovation and implications for capability development. Technovation, 25(3), 171-183.

Garcia, R., \& Calantone, R. (2002). A critical look at technological innovation typology and innovativeness terminology: a literature review. Journal of Product Innovation Management: An international publication of the product development \& management association, 19(2), 110-132.

Gold, A. H., Malhotra, A., \& Segars, A. H. (2001). Knowledge management: An organizational capabilities perspective. Journal of management information systems, 18(1), 185-214.

Gray, R. (2010). Is accounting for sustainability actually accounting for sustainability... and how would we know? An exploration of narratives of organisations and the planet. Accounting, Organizations and society. 35(1), 47-62.

Gurbiel, R. (2002). Impact of innovation and technology transfer on economic growth: the central and Eastern Europe experience. Warshaw School of Economics, 162, 1-18.

Gurteen, D. (1998). Knowledge, Creativity and Innovation. Journal of Knowledge Management, Vol. 2 No. 1, pp. 5-13. https://doi.org/10.1108/13673279810800744.

Hagedoorn, J. (1993). Understanding the rationale of strategic technology partnering: Interorganizational modes of cooperation and sectoral differences. Strategic management journal, 14(5), 371-385.

Henderson, R. M., \& Clark, K. B. (1990). Architectural innovation: The reconfiguration of existing product technologies and the failure of established firms. Administrative science quarterly, 9-30.

Heunks, F. J. (1998). Innovation, creativity and success. Small Business Economics, 10(3), 263272.

Janz, B. D., \& Prasarnphanich, P. (2003). Understanding the antecedents of effective knowledge management: The importance of a knowledge-centred culture. Decision Sciences, 34(2), 351-384.

Jun, J. W., \& Lee, H. S. (2007). Cultural differences in brand designs and tagline appeals. International Marketing Review.

Koellinger, P. (2008), The relationship between technology, innovation, and firm performanceEmpirical evidence from e-business in Europe. Research Policy, 37(8), 1317-1328.

Lee, K., Rho, S., Kim, S., \& Jun, G. J. (2007). Creativity-innovation cycle for organisational exploration and exploitation: lessons from Neowiz-a Korean internet company. Long Range Planning, 40(4-5), 505-523.

Lee, S., \& Park, Y. (2005). Customization of technology roadmaps according to roadmapping purposes: Overall process and detailed modules. Technological forecasting and social change, 72(5), 567-583.

Malecki, E. J. (2010). Global knowledge and creativity: new challenges for firms and regions. Regional studies. 44(8), 1033-1052.

Martins, E.C. \& Terblanche, F. (2003). Building organisational culture that stimulates creativity and innovation. European Journal of Innovation Management, Vol. 6 No. 1, pp. 6474. https://doi.org/10.1108/14601060310456337

McGivern, M.H. \& Tvorik, S.J. (1998). Vision driven organizations: measurement techniques for group classification. Management Decision, Vol. 36 No. 4, pp. 241-64.

Melewar, T. C., \& Jenkins, E. (2002). Defining the corporate identity construct. Corporate reputation review, 5(1), 76-90.

Melewar, T. C., \& Jenkins, E. (2002). Defining the corporate identity construct. Corporate 
reputation review, 5(1), 76-90.

Mogee, M. E. (1993). Educating innovation managers: Strategic issues for business and higher education. IEEE Transactions on Engineering Management, 40(4), 410-417.

Mohtar, L. E., Halim, L., \& Sulaiman, S. (2015). Dependence on Creativity Characteristics as Observed during the Implementation of Laboratory Activities. Creative Education, 6(11), 1168.

Moore, G.C. and Benbasat, I. (1991). Development of an instrument to measure the perceptions of adopting an information technology innovation. Information Systems Research. Vol. 2 No. 3, pp. 192-222.

Mosloo, A., Damneh, K. T. M., \& Jalilian, N. (2009). Investigate the role of knowledge management in public organizations to improve employees' creativity (Case study: Hospital Sadoughi). Paper presented at Second National Conference of creativity, Engineering and Innovation Management, Iran.

Mumford, M. D., \& Gustafson, S. B. (1988). Creativity syndrome: Integration, application, and innovation. Psychological bulletin. 103(1), 27.

Nielsen, A. P. (2006). Understanding dynamic capabilities through knowledge management. Journal of knowledge management.

Nieminen, J. (2019). Incremental Innovation - The What, Why, and How. Retrieved on 16.4.2021. https://www.viima.com/blog/incremental-innovation

Price, J. L. (2001). Reflections on the determinants of voluntary turnover. International Journal of manpower.

Prusak, L., \& Davenport, T. (1998). Working knowledge: how organizations manage what they know.

Rank, J., Pace, V. L., \& Frese, M. (2004). Three avenues for future research on creativity, innovation, and initiative. Applied psychology, 53(4), 518-528.

Sternberg, R. J., \& Lubart, T. I. (1999). The concept of creativity: Prospects and paradigms. Handbook of creativity, 1, 3-15.

Zhou, J., \& Shalley, C. E. (2003). Research on employee creativity: A critical review and directions for future research. Research in personnel and human resources management.

O'Connor, G. C., \& Veryzer, R. W. (2001). The nature of market visioning for technology-based radical innovation. Journal of Product Innovation Management: An International Publication of the Product Development \& Management Association, 18(4), 231-246.

Park, J. G., \& Lee, J. (2014). Knowledge sharing in information systems development projects: Explicating the role of dependence and trust. International Journal of Project Management, 32(1), 153-165.

Pavitt, K. (1999). Technology, management and systems of innovation. Edward Elgar Publishing.

Plewa, C., Troshani, I., Francis, A., \& Rampersad, G. (2012). Technology adoption and performance impact in innovation domains. Industrial Management \& Data Systems

Prendergast, C. (2000). The triangle of representation. Columbia University Press.

Rahimnia, F., Moghadasian, M., \& Mashreghi, E. (2011). Application of grey theory approach to the evaluation of organizational vision. Grey Systems: Theory and Application.

Rogers, E.M. (2003). Diffusion of Innovations, The Free Press, New York, NY.

Sarooghi, H., Libaers, D., and Burkemper, A. (2015). Examining the relationship between creativity and innovation: A meta-analysis of organizational, cultural, and environmental factors, Journal of Business Venturing, Volume 30, Issue 5, Pages 714-731

Schilling, M. A. (2002). Technology success and failure in winner-take-all markets: The impact of learning orientation, timing, and network externalities. Academy of Management Journal, 45(2), 387-398.

Smith, M., Busi, M., Ball, P., and Van der Meer, R. (2008). Factors influencing an organisation's ability to manage innovation: a structured literature review and conceptual model. International Journal of innovation management, Vol 12, Issue 04, Pages 655-676

Sternberg, R. J. (2012). The assessment of creativity: An investment-based approach. Creativity 
research journal, 24(1), 3-12.

Vehar, J. (2013). Creativity and Innovation: What Is the Difference?. In: Carayannis E.G. (eds) Encyclopedia of Creativity, Invention, Innovation and Entrepreneurship. Springer, New York, NY.

Weisberg, R. W. (1999). Creativity and knowledge: A challenge to theories. In R. J. Sternberg (Ed.), Handbook of creativity (p. 226-250). Cambridge University Press.

West, M. A. (2002). Sparkling fountains or stagnant ponds: An integrative model of creativity and innovation implementation in workgroups. Applied psychology, 51(3), 355-387.

Wieneke, S., \& Phlypo-Price, K. (2010). The Knowledge Management and Application Domain. Wieneke \& Wieneke Inc.

Yli-Renko, H., \& Janakiraman, R. (2008). How customer portfolio affects new product development in technology-based entrepreneurial firms. Journal of marketing. 72(5), 131-148.

Zhao, Y., Lu, Y. and Wang, X. (2013). Organizational unlearning and organizational relearning: a dynamic process of knowledge management, Journal of Knowledge Management, Vol. 17 No. 6, pp. 902-912.

Zhong, W. J., Mei, S. E., \& Xie, Y. Y. (2009). Analysis of technological innovation modes for the industry-university-institute cooperation [J]. China Soft Science, 8, 176. 